\title{
O contexto político e o discurso da ciência da informação no Brasil: uma análise a partir do Ibict
}

Eduardo Vieira Martins

Doutorando em CI do Ibict. Tecnologista do CICT/Fiocruz E-mail:emartins@cict.fiocruz.br

\section{Resumo}

Desde suas origens, a ciência da informação no Brasil esteve estreitamente vinculada ao sistema governamental de C\&T, o que implicou sua estreita relação com as políticas de Estado. As mudanças políticas e ideológicas por que passou o país nos últimos 50 anos influíram de forma marcante nos caminhos percorridos pela $\mathrm{Cl}$. A discussão de como as ideologias e as políticas públicas influenciaram a $\mathrm{Cl}$, a partir da análise do Ibict, pode fornecer instrumentos para entender o momento atual e pensar o futuro da $\mathrm{Cl}$ no país.

\section{Palavras-chave}

Políticas de informação; Estado; Sociedade da informação; Ibict.

The political context and the discurse of the of information science in Brasil: an analyse from the Ibict

\begin{abstract}
Information Science in Brasil, in its origin was linked to $R \& D$ government system which caused its evolution well related to the govern politics. The ideological and political changes, in the last 50 years, influenced strongly the paths of IS. The discussion of how the ideologies and public policies influenced IC from the Ibictanalises, may supply instruments for us to understand the present moment and make us think about IC's future in Brasil.
\end{abstract}

\section{Keywords}

Information policies; Government; Information society; Ibict.
"Parece que nos aproximamos de uma temível revolução na história do saber, em que ele, deixando de ser pensado, meditado, refletido e discutido por seres humanos, integrado na investigação individual e de sabedoria, se destina cada vez mais a ser acumulado em bancos de dados, para ser, depois, computado por instâncias manipuladoras, o Estado em primeiro lugar."

\section{Edgar Morin (Ciência com Consciência,} 1999, p. 17).

\section{INTRODUÇÃO}

A ciência da informação (CI) tem sido estudada e analisada no Brasil por inúmeros autores, seja a partir de sua gênese na biblioteconomia, ou de outros elementos que, na história de seu desenvolvimento, a ela se incorporaram e passaram a ser objeto de estudo da nova disciplina.

Entretanto, em nosso entender, os fatos políticos que conformaram a sociedade nesses quase 50 anos de vida da ciência da informação no Brasil foram fundamentais para seu perfil atual e continuam sendo importantes na definição dos caminhos que a disciplina vem trilhando e poderá seguir no futuro.

Fundamental tem sido, na curta história da CI no Brasil, o papel do Estado, que foi o indutor de sua implementação, sem que possamos, entretanto, desconsiderar o importante trabalho empreendido por alguns atores que influenciaram, de forma marcante e mesmo decisiva, o delineamento da proposta e o arcabouço teórico que lhe deu a conformação atual.

A CI, como qualquer atividade científica, deve ser analisada dentro do contexto em que se desenvolve, pois "o poder em migalhas no nível da investigação encontrase reconcentrado no nível dos poderes econômicos e políticos” (Morin, 1999), que, em última instância, são os poderes que, a partir das "migalhas de informação", constroem os cenários para determinar os caminhos que deverão ser percorridos pela ciência e pelos cientistas. 
Ao analisarmos a informação na perspectiva apontada por Belkin \& Robertson (1976) como elemento de transformação de estruturas conceituais sociais, é importante considerar a serviço de quem ou do que está a informação. Nesse contexto, o Estado, que é o formulador das políticas e ator preferencial em sua implementação, determina, ou, no mínimo, induz ideologicamente a direção ou os caminhos dessa transformação de estruturas sociais.

No presente trabalho, mesmo correndo os riscos que uma simplificação oferece, procuramos fazer uma análise dos caminhos percorridos pela jovem ciência da informação no Brasil e dos fatos políticos que, se nem sempre foram determinantes, influenciariam de forma importante o seu desenvolvimento. Acreditamos que esse tipo de abordagem possibilita uma reflexão sobre os fatos que vêm ocorrendo e suas possíveis repercussões na política científica e tecnológica e nos rumos da CI.

Para tal análise, utilizamos os eventos e decisões que, de alguma forma, influenciaram as políticas científica e tecnológica. A partir de 1972, além dos fatores citados, agregamos dados da freqüência dos recortes discursivos do periódico Ciência da Informação e da produção discente das dissertações de mestrado e teses de doutorado produzidas no curso de CI do Instituto Brasileiro de Informação em Ciência e Tecnologia (Ibict) em convênio com a Universidade Federal do Rio de Janeiro (UFRJ), dados constantes na tese de Freitas $(2001)^{*}$. Esses dados possibilitaram constatar quais os temas que mais mobilizaram os pesquisadores e estudantes da ciência da informação no país. Nas dissertações e teses produzidas, consideramos um período médio de quatro anos de elaboração de trabalhos, ou seja, aqueles apresentados em 1990, por exemplo, refletem as preocupações da área em 1986.

\section{O CONTEXTO BRASILEIRO NO PÓS-GUERRA}

O mundo saiu da II Guerra, em 1945, com uma nova correlação de forças, dividido entre os líderes da vitória: os Estados Unidos e a União Soviética. As diferenças ideológicas entre os principais vencedores e os interesses de sua hegemonia e dominação sobre as nações deram início a uma surda disputa, a Guerra Fria. A explosão de bombas atômicas sobre o Japão evidenciou que a ciência poderia ser elemento importante para a expansão do poderio militar e contribuir para a hegemonia política

\footnotetext{
* As áreas que a autora considerou para esses recortes discursivos foram cultura, ciência, política, economia gerencial, perspectiva histórico-social tradicional e perspectiva histórico-social nova.
}

mundial. Nesse contexto, a informação tornou-se uma prioridade para as nações, uma vez que o conhecimento científico passou a ter valor estratégico para o desenvolvimento do aparato industrial bélico-militar.

O Brasil, ao final da II Guerra, sofreu significativa mudança política com a saída de Getúlio Vargas da Presidência da República e o fim do Estado Novo, a eleição de Eurico Dutra e a instalação da Assembléia Nacional Constituinte. O governo Dutra significou o abandono do projeto nacionalista de Vargas e o alinhamento do Brasil à política e aos interesses apontados pelos Estados Unidos.

O domínio da ciência e principalmente da energia nuclear se configurava, então, como uma necessidade estratégica e de soberania das nações. Naquele momento, um grupo de pesquisadores brasileiros, percebendo a importância que a ciência adquiria no novo contexto mundial, fundou em 1948 a Sociedade Brasileira para o Progresso da Ciência (SBPC) "como fruto de um movimento de afirmação do pensamento científico [com a finalidade de] lutar pelo progresso da ciência..." (SBPC, 2001), quando havia um consenso da "[...] necessidade de se preparar quanto antes o nosso país para a utilização técnico-científica de nossos recursos minerais de interesse para a produção da energia atômica*" (Ribeiro,1994, p. 209).

Em 1946, o almirante engenheiro Álvaro Alberto da Motta e Silva, representante brasileiro na Comissão de Energia Atômica do Conselho de Segurança, da recémcriada Organização das Nações Unidas (ONU), propôs ao governo, por intermédio da Academia Brasileira de Ciências, a criação de um conselho nacional de pesquisa, mas, somente em 1949, o presidente Dutra nomeou comissão para apresentar projeto de lei sobre a criação do conselho de pesquisa. Após debates em diversas comissões da Câmara dos Deputados, em 15 de janeiro de 1951, dias antes da posse de Getúlio Vargas, foi criado o Conselho Nacional de Pesquisas (CNPq), com o objetivo principal de "promover o desenvolvimento da investigação científica e tecnológica em todos os domínios do conhecimento" (art. 1ํ da Lei 1310 de 15/11/1951) (CNPq, 2001). O CNPq assumiu, então, nos anos seguintes, a formulação das políticas de ciência e tecnologia no país, bem como a coordenação dessas atividades.

\footnotetext{
* Inúmeros países desenvolveram programas nucleares. A Rússia testou sua bomba atômica em 1949. A França colocara em 1948 um reator nuclear em funcionamento. Em 1952, Holanda e Noruega, consorciadas, iniciaram a operação de um reator projetado e construído sem o concurso de militares. Outros países como Tcheco-Eslováquia, Polônia, Índia e Argentina possuíam programas nucleares em andamento (Montayama \& Marques, 1994).
} 
O contexto político e o discurso da ciência da informação no Brasil: uma análise a partir do Ibict

\section{O PERÍODO 1951-1955 - O RETORNO DE VARGAS}

Primeiro presidente do CNPq, o almirante Álvaro Alberto incentivou fortemente a formação de profissionais na área de energia atômica (CNPq, 2001). Álvaro Alberto, nacionalista autonomista, tentou, com o apoio de Vargas, implementar uma política de capacitação nuclear com outros parceiros, que não os americanos. Foi feito um projeto para a instalação de um reator com a França e Alemanha que não se concretizou, devido à intervenção do Alto Comissariado de Ocupação da Alemanha, que impediu a entrega dos equipamentos (Montayama \& Marques, 1994). Essa medida frustrou a queima de etapas na implantação de um projeto nuclear no Brasil. Entretanto, alguns autores questionam a incapacidade do Brasil para aquisição de aceleradores de partículas, que poderiam ser comprados, sem restrições, de algumas empresas no mercado internacional.

O segundo Governo Vargas foi marcado pelo retorno de seu projeto nacionalista de implementação da indústria de base, que incluía a expansão da siderurgia, construção de hidrelétricas, refinarias de petróleo, usinas de nitrogênio e álcalis, bem como o apoio à modernização do parque industrial (Montayama \& Marques, 1994). Essas iniciativas exigiam a capacitação de recursos humanos, a formação de pesquisadores, o fortalecimento e o incentivo à pesquisa para desenvolver uma indústria que pretendia substituir importações e tornar o país autosuficiente em produtos básicos. Nesse projeto, o conhecimento constituía-se em valor estratégico.

A política científica desenvolvida pelo CNPq procurava desvincular-se dos cânones ditados pelos norteamericanos e, seguindo a tendência européia, preconizava que, para fazer políticas de desenvolvimento científico, seria fundamental tratar a informação científica a partir do conteúdo da publicação, e não a partir da publicação em si. Nessa perspectiva, foi criado em 1954, no âmbito do CNPq, o Instituto Brasileiro de Bibliografia e Documentação (IBBD), com decisivo apoio da Organização das Nações Unidas para a Educação, a Ciência e a Cultura (Unesco), que criara o "programa Unisist (Sistema Mundial de Informação Científica e Tecnológica)" dedicado à informação científica (Zaher,1995). A Unesco vinha então promovendo a criação de centros nacionais de documentação para apoiar as instituições científicas, técnicas e industriais, pois tais centros exerceriam importante papel para a pesquisa científica e a educação superior e teriam ainda importância fundamental para o desenvolvimento dos países (Pinheiro, 1997).
Em 1955, foi criado, no IBBD, o Curso de Documentação Científica/Curso de Especialização em Informação e Documentação (CDC), com o propósito de disseminar conhecimentos sobre os processos de geração, tratamento, recuperação e disseminação da informação científica e tecnológica. Esse curso tornou-se, nos anos seguintes, espaço de reflexão e discussão sobre os caminhos da informação no Brasil e do objeto de trabalho IBBD (Christovão, 1995).

\section{O PERÍODO 1956-1960, NACIONAL DESENVOLVIMENTISTA}

O Governo Juscelino Kubitschek adotou uma política desenvolvimentista, com a implantação de um ambicioso projeto industrial de bens duráveis e interiorização do desenvolvimento, tendo como um dos instrumentos para sua execução a liberalização da economia. Nesse processo de industrialização, o empresariado nacional, refratário à intervenção do Estado na economia, recorreu ao capital estrangeiro e importou tecnologias, alijando, assim, o sistema técnico científico existente no país do processo de industrialização (Cardoso, 1964). Portanto, nesse período, a influência estrangeira, principalmente do capital e da ideologia dos Estados Unidos sobre as políticas brasileiras, foi preponderante. Tal ideologia influenciou a pesquisa científica brasileira, que passou a ter como agenda de trabalho as propostas americanas. Na área da informação, a influência preponderante era ainda a européia, pois o governo americano ainda não entendera a sua importância, o que veio a acontecer apenas ao final da década.

No Brasil, o IBBD vinha seguindo a orientação da Unesco, cujo programa de informação foi fortemente influenciado pelos soviéticos que possuíam um Estado centralizado e planificado no qual a informação se materializava como força produtiva. Os soviéticos possuíam o Instituto Russo de Informação Científica e Tecnológica $\left(V\right.$ initi) ${ }^{*}$, cuja metodologia foi a base do sistema da Unesco. Mikhailov, membro do Viniti e da Academia de Ciências da União Soviética, que considerava a informação insumo importante para o planejamento e ações estratégicas de governo, foi um dos formuladores dos documentos que direcionaram as propostas da Unesco na área.

Esse papel estratégico da informação foi assumido pelo IBBD, que adotou uma política de formação de recursos humanos para todo o país e recebeu também alunos de vários países da América Latina. A principal

\footnotetext{
* Em 1983, quando do trabalho citado, o Viniti produzia mensalmente cerca de um milhão de documentos distribuídos em 150 bancos de dados (Mikhailov, 1983).
} 
conseqüência da proposta desses cursos foi uma mudança importante na visão da biblioteconomia no país, com a introdução de uma nova lógica na atuação dos profissionais da área. O CDC foi o embrião do mestrado em ciência da informação, criado em 1970, que passou a formar profissionais oriundos de várias áreas do conhecimento, o que ampliou a discussão sobre a CI no país (Zaher, 1995), como veremos, posteriormente.

Em 1957, a URSS lançou o Sputnik no espaço, fato que surpreendeu os americanos, que formaram então uma comissão para estudar por que um país tecnologicamente menos avançado teria conseguido tal feito. $\mathrm{O}$ resultado deste trabalho foi o relatório Weinberg, que destacou, tardiamente em relação à Europa, a necessidade de estabelecer uma política de informação científica, em âmbito governamental* (Freitas, 2001). A conseqüência foi a implementação de um sistema de informação científica que possibilitaria ao governo conhecer o estado-da-arte da pesquisa no país e, com isso, estabelecer políticas nacionais para os programas espacial e militar. Esses fatos são importantes para se entender como se formou a CI nos Estados Unidos, que privilegiou, nos anos seguintes, a automação dos sistemas de registro e recuperação da informação como forma de conhecer a capacidade científica e tecnológica disponíveis no país. Essa nova concepção de uso da informação influenciou, de forma importante, os rumos do IBBD nos anos 60 .

\section{O INÍCIO DOS ANOS 60 - A INSTABILIDADE POLÍTICA}

O Brasil viveu, no período 1961/64, momentos de grande instabilidade política. O governo Jânio Quadros culminou com a sua renúncia após sete meses de governo. O governo João Goulart durou 30 meses, sendo um ano de parlamentarismo conturbado e, no período presidencialista, quando pregava o não-alinhamento aos Estados Unidos, teve a oposição das forças conservadoras e instabilidade política como uma constante. Tais fatores desestabilizaram de tal forma seu governo, que criaram as condições para o golpe de Estado, ocorrido em março de 1964. Nesses pouco mais de três anos de governo, as propostas formuladas em nível governamental não chegaram a se consubstanciar em programas efetivos na área de política científica e, muito menos, em uma política para a área de informação.

\footnotetext{
* As agências governamentais que se voltaram à informação científica e tecnológica ou a serviços especializados nas áreas de energia atômica, saúde mental e medicina a partir daquele momento foram as seguintes: National Aeronautics and Space Administration (Nasa), Science Information Exchange, National Referral Center e Committee on Scientific and Technical Information (Freitas, 2001).
}

Entretanto, na sociedade brasileira, as discussões sobre o papel dos profissionais no processo político e de desenvolvimento dominavam a agenda acadêmica ainda envolvida pela discursividade desenvolvimentista e nacionalista. Fato importante foi a realização, em 1963, do $4^{\circ}$ Congresso Brasileiro de Biblioteconomia e Documentação (CBBD), no qual, pela primeira vez, fez-se referência à ciência da informação. $\mathrm{O}$ evento teve como tema central A Biblioteca como Fator de Progresso, com a discussão de temas como informação científica e informação em empresas e indústrias (Freitas, 2001).

\section{OS GOVERNOS MILITARES 1964/84 - O ESTADO PLANEJADOR}

A ascensão dos militares ao poder privilegiou a "segurança nacional”, o que não significou, nos 24 anos que ali permaneceram, uma hegemonia de pensamento quanto às políticas de desenvolvimento econômico ou aos rumos da política científica, tecnológica e industrial. A ciência, a tecnologia e a informação, nesse período, passam a ser consideradas como fatores vinculados à segurança nacional, portanto deveriam ser controladas pelo Estado, mesmo que nos diversos governos apresentassem por vezes ambigüidade quanto às prioridades que lhes eram dadas (Santos, 1999).

O Governo Castello Branco (1964 -1967), marcado pela "caça às bruxas", procurou excluir da sociedade os elementos considerados "subversivos", que poderiam colocar em discussão a nova ordem que se instalava no país. A comunidade científica esteve ameaçada, pois as perseguições políticas a quem discordasse do regime significavam suspensão de direitos políticos e aposentadoria compulsória.

Na área econômica, criou-se o Plano de Ação Econômica do Governo (Paeg), que privilegiava a importação de tecnologia. No plano político, o Brasil se alinhou aos Estados Unidos, aumentando a dependência econômica e atrelando os projetos político, industrial e de desenvolvimento nacional aos interesses ditados pelos norte-americanos, que se utilizavam da United States Agency International Development (Usaid) em programas de apoio ao país.

Segundo Souza, em 1966, sob os auspícios da Usaid e do CNPq, um grupo de trabalho composto por técnicos e pesquisadores brasileiros e norte-americanos propunha em documento "[...] medidas capazes de dar suporte informacional ao desenvolvimento econômico brasileiro [...]" e ao final do documento recomendava: 
“[...] o reconhecimento, aproveitamento e emprego da informação, ao invés da pura e simples catalogação e acumulação [...; ] reorganizar o IBBD, [...] orientando e coordenando uma rede brasileira de informação e documentação. [Com] dinamismo e flexibilidade bastante para ele operar de acordo com padrões de uma "documentação agressiva", suprindo a informação necessária às organizações técnico-científicas, em base prioritária [; e] modernizar e expandir o preparo de bibliotecários e especialistas em documentação, reformulando os programas de ensino vigentes [...] Souza conclui: Foi nesse sentido que, ao estilo norte-americano de formação de cientistas da informação, o IBBD implantou seu mestrado em ciência da Informação". (Souza, 1990, p. 73)

Foi esse o pensamento que passou a influenciar o IBBD ao implantar, com essas diretrizes, em 1970, o mestrado em ciência da informação, de acordo com a linha norteamericana.

O Governo Costa e Silva (1967-1969) fez opção pelo crescimento econômico e formulou o Programa Estratégico de Desenvolvimento (PEG), que propunha uma política científico-tecnológica voltada para o crescimento industrial e substituição de importações. Realizou a Reforma Universitária, que conjugava a desconcentração dos estudantes nas unidades de ensino, o que era interessante para diminuir as manifestações contra o governo, com o aumento da oferta de cursos e especialidades tecnológicas, fundamentais para suprir o mercado de mão-de-obra especializada. Houve grande expansão da pós-graduação, e a "operação retorno", que pretendia reabsorver os pesquisadores que haviam abandonado o país, fracassou, pois estava condicionada aos imperativos da segurança nacional (Santos, 1991).

Em 1968, foi realizado o Seminário de Informática (no sentido de CI), promovido pelo IBBD e considerado o "marco fundador da CI no Brasil (Freitas, 2001). Iniciase, então, no IBBD a "gestação" do mestrado em ciência da informação, com o convite a vários professores recrutados nos Estados Unidos e Inglaterra, como também a busca de apoio financeiro para a vinda dos mesmos, o que foi conseguido junto à Unesco, Consulado Americano, Fundação Ford, Conselho Britânico e Comissão Fullbright (Zaher, 1995; Freitas, 2001). Essas iniciativas possibilitaram o início do curso de mestrado em 1970.

\footnotetext{
* CONSELHO NACIONAL DE PESQUISA. A pesquisa industrial no Brasil como fator de desenvolvimento. Rio de Janeiro, 1968.
}

O Governo Médici (1969-1974) construiu o discurso do "Brasil potência", com o fortalecimento da indústria nacional por meio do desenvolvimento de tecnologias, o que estava previsto no I Plano Nacional de Desenvolvimento (PND) e detalhado no I Plano Básico de Desenvolvimento Científico e Tecnológico (PBDCT).

"De fato o 1० PBDCT representa 'a nota que faltava', segundo as palavras do ministro [Reis Veloso], no contexto em que o planejamento é parte integrante do processo de modernização, obedecendo a critérios tecnocráticos de eficiência e racionalidade, sendo o Estado a principal agência planejadora" (Morel, 1979, p. 66).

Entretanto, a implementação dessas propostas não aconteceu como se esperava, pois a Secretaria de Planejamento da Presidência da República, à qual estava vinculado o sistema de Ciência e Tecnologia (C\&T) e o Ministério da Fazenda, condutor da política econômica, que não se articulavam ou mesmo não comungavam dos mesmos princípios (Santos, 1999).

Em 1970, inicia-se o primeiro mestrado em CI no Brasil, de acordo com as propostas do grupo de trabalho de 1966, que, ao possuir uma:

"[....] filiação a políticas de Estado modernizantes, confere caráter bastante especial às práticas e à reflexão desenvolvidas no seio da instância responsável pelo programa de pesquisa e pós-graduação que influenciou fortemente outros cursos de pós-graduação em informação no Brasil” (Freitas, 2001, p.87).

O curso de mestrado, a partir de seu "amadurecimento", passou a formar pesquisadores e profissionais, oriundos de diversas áreas do conhecimento, com trabalhos voltados para outras áreas de aplicação da $\mathrm{CI}$, que não a biblioteconomia. Isso se reflete nos artigos do periódico Ciência da Informação, que nos anos 1972/1973 tiveram, como recortes discursivos predominantes, a ciência, e na produção discente do curso de CI do Ibict, que apresenta, com maior freqüência, o tema ciência, seguido por economia gerencial e por cultura (Freitas, 2001).

O tema Informação estava contemplado no I PND, no qual se previa a implantação de um Sistema Nacional de Informação em Ciência e Tecnologia (SNICT), cuja idéia foi aprofundada e detalhada no I PBDCT (1973/ 74), no qual estava estabelecido como objetivo principal do SNITC: 
“... captar, tratar e difundir, de forma sistemática e permanente, informações atualizadas na área de ciência e tecnologia, assim como os vários subsistemas que dele participariam com suas respectivas áreas de atuação" (I PBCT, 1976 apud Pinheiro, 1997).

O SNICT, que estabeleceria uma rede nacional de intercâmbio no campo da documentação, deveria ficar vinculado ao CNPq e funcionar de forma descentralizada, utilizando como órgão de apoio o IBBD e a Biblioteca Nacional. Entretanto, o Sistema não chegou a ser implantado (Pinheiro, 1976).

O Governo Geisel (1974-1978), em função da crise do petróleo, colocou como prioridade a consolidação do parque industrial de base, mediante investimentos, subsidiados por crédito externo e um programa de desenvolvimento científico e tecnológico que, contemplado no II PND, propugnava um "nacionalismo positivo" e o "domínio de tecnologia sofisticada", encarando a ciência e tecnologia como agentes do desenvolvimento econômico e social, o que, segundo Santos (1999), aproximava-o "mais da perspectiva do segundo governo Vargas”, distanciando-se de um alinhamento automático com os Estados Unidos.

A transformação do Ministério do Planejamento em Secretaria do Planejamento e Coordenação Geral da Presidência da República a coloca como coordenadora do Sistema Nacional de Desenvolvimento Econômico e Social, vinculando a ela o Banco Nacional de Desenvolvimento Econômico e Social (BNDES), o Instituto de Pesquisa Econômica Aplicada (Ipea), a Financiadora de Estudos e Projetos (Finep), o CNPq e o Instituto Brasileiro de Geografia e Estatística (IBGE), colocando em suas mãos os instrumentos de planejamento, de fomento, de C\&T e de informação.

No II PBDCT (1975/79), a informação científica e tecnológica foi incluída entre as atividades de apoio ao desenvolvimento científico e tecnológico e foi considerada como "[...] elemento básico de apoio para a formulação de políticas e estratégia do governo”. Em 1976, o IBBD é substituído pelo Instituto Brasileiro de Informação em Ciência e Tecnologia, que absorve algumas atribuições e características que estavam destinadas ao SNICT (Pinheiro, 1997).

Assim, no governo Geisel, o Ibict surge “[...] como órgão de fomento e coordenação com a missão de promover a efetivação do Sistema Nacional de Informação em Ciência e Tecnologia" (Pinheiro, 1997), fato que se reflete em sua produção científica.
Nesse período, nas publicações do periódico Ciência da Informação e na produção discente do curso de CI do Ibict, os temas de maior incidência são, em primeiro lugar, a ciência, seguido pela cultura (Freitas, 2001).

O Governo Figueiredo (1980-1985) foi marcado pela abertura democrática, o que permitiu a liberdade da discussão política e a volta dos exilados ao país.

Na área de C\&T, foi editado o III PBDCT, que atribui ao Ibict o papel de "órgão central com condições institucionais e materiais para desempenhar funções de coordenação descentralizada das atividades de informação em ciência e tecnologia no país". Os projetos e programas estavam em documentos específicos, denominados "ações programadas", sendo importante destacar:

- Ação Programada de Informação Científica e Tecnológica (1984), da qual participaram mais de 100 profissionais da área de informação;

- Programa de Apoio ao Desenvolvimento Científico e Tecnológico (PADCT), que apoiou o Ibict e outros sistemas em áreas priorizadas pelo $\mathrm{CNPq}$;

- Plano Nacional de Bibliotecas Universitárias (PNBU), surgido em 1986.

Essas "ações programadas" influíram no crescimento do Ibict, que passou a participar efetivamente dos seguintes sistemas:

- Rede Antares (acesso descentralizado a bases de dados);

- Programa Brasileiro de Qualidade e Produtividade (PBQP);

- Programa de Apoio à Capacitação Tecnológica da Indústria (PBCTI);

- Catálogo Coletivo Nacional de Publicações Seriadas (CCN);

- Programa de Comutação Bibliográfica (Comut).

Além disso, o Ibict produzia bancos de dados para a Rede Nacional de Pesquisa (RNP) e Rede Nacional de Computação por Pacote (Renpac) da Empresa Brasileira de Telecomunicação (Embratel) (Ribeiro, 1997).

É importante assinalar que, nesse período, os sistemas eletrônicos tornaram-se acessíveis às instituições de ensino e pesquisa. Entretanto, sua utilização exigia que os bancos de dados fossem centralizados, o que fez com que o Ibict assumisse sua liderança. 
O contexto político e o discurso da ciência da informação no Brasil: uma análise a partir do Ibict

Nesse período, a produção do periódico Ciência da Informação tinha como principais recortes discursivos a ciência, a cultura e a economia gerencial. Já na produção discente do Curso de CI do Ibict, os temas foram os mesmos, apenas em outra ordem, ou seja, economia gerencial, ciência e cultura (Freitas, 2001).

\section{A VOLTA AO ESTADO DE DIREITO 1985/89 - O REORDENAMENTO DAS FORÇAS SOCIAIS}

O Governo Sarney representou o fim da ditadura militar no Brasil, o que provocou um amplo movimento da sociedade para reordenar o Estado, sob a égide da liberdade e da democracia. Embora a economia estivesse convivendo com altas taxas de inflação e forte desequilíbrio nas contas públicas, houve grande movimento para o fortalecimento das instituições, na busca de ocupação de espaços pelos atores sociais e de mudança nos processos autoritários de gestão dos órgãos públicos.

O Ibict amplia seus espaços de atuação, e, então, o mestrado cria a linha de pesquisa "informação, cultura e sociedade”, que passa, posteriormente, a ser área de concentração (Ribeiro, 1997), o que mostra como os "ventos políticos" podem ser capazes de induzir o direcionamento das linhas de trabalho e pesquisa das instituições.

Neste período, os temas predominantes no periódico Ciência da Informação foram ciência, cultura, economia gerencial e política; na produção discente do curso CI do Ibict, cultura, ciência, política e economia gerencial.

Podemos, portanto, verificar que, de sua criação em 1955 até 1990, o Ibict teve suas atividades voltadas para a ciência em um projeto de desenvolvimento nacional e, em alguns momentos, para as necessidades tecnológicas de empresas privadas, que eram parte integrante desse projeto. As mudanças na ordem internacional e a popularização da Internet, que ocorreram nos anos seguintes, influenciam de forma substantiva, como veremos a seguir, a agenda de trabalho e os focos de estudos do Ibict.

\section{A OPÇÃO NEOLIBERAL 1990/94 - O DOMÍNIO DO CAPITAL INTERNACIONAL}

A posse do Governo Collor, em 1990, foi seguida de uma abertura da economia ao mercado internacional, de acordo com os ditames do "Consenso de Washington”. Como conseqüência imediata, a indústria nacional entra em crise pela incapacidade de competir com os produtos importados. Ocorre, então, uma ampla reestruturação da qual sobreviveram apenas aquelas indústrias que se modernizaram ou que se associaram para realizar os investimentos necessários para torná-las competitivas.

O fim da reserva de mercado na área de informática possibilitou a disseminação do microcomputador nas instituições e mesmo nos domicílios. $\mathrm{O}$ acesso a bancos de dados e à Internet causou uma verdadeira revolução no acesso à comunicação e informação, que passaram a ser disponíveis em "tempo real”. O Ibict inicia pesquisas sobre as redes de comunicação, incorporadas ao curso do mestrado.

Os recortes discursivos predominantes no periódico Ciência da Informação foram política, em primeiro lugar, seguido de economia gerencial e ciência, e, na produção discente dos cursos do Ibict, predominaram política, cultura, ciência e economia gerencial (Freitas, 2001).

Esse novo domínio da importância do discurso político sobre as ciências sociais provocou uma reflexão sobre os percursos que a CI vinha percorrendo e as rupturas que fizera no passado. Assim, Marcos Dantas, em sua análise, diz "[...] em última instância, é o receptor quem determina, dialeticamente, a qualidade do processo informacional, pois é ele quem orienta a ação, em função das escolhas que faz na informação que recebe”. Vânia Araújo (1994) afirma que "[...] os construtos teóricos dos sistemas de informação precisam voltar-se para o Caos e rever-se à luz dessa nova teoria, buscando uma inserção mais adequada para suas próprias teorias, leis, quase-lei, modelos conceitos etc." Aldo Barreto afirma que "a informação sintoniza o homem”. Esses pesquisadores vêm dar novo enfoque para a questão da informação, na qual ela ganha um sentimento político dentro do espaço social no qual está inserida.

\section{A CONSOLIDAÇÃO DO NEOLIBERALISMO $1995-2000$}

A opção do governo, já sob o comando de Fernando Henrique Cardoso, seguindo a doutrina neoliberal proclamada pelos agentes financeiros internacionais, foi a privatização das empresas estatais, entre elas as que constituíam o sistema de telecomunicações, uma vez que o Estado não dispunha de recursos para financiar a expansão e modernização que as novas redes e sistemas de comunicação de dados e de informação exigiam.

A “explosão da Internet” em meados da década de 90, aliada ao novo modelo neoliberal, que nos discursos políticos seria um fato irreversível, influencia de forma importante os cursos de pós-graduação que incorporam: 
"[...] os discursos ligados às sociedades ocidentais contemporâneas como pós-industriais [e] nos temas voltados para o cultural, vemos disseminarem-se as abordagens baseadas na noção de pós-modernidade" que se reflete na produção textual "de temas também dominantes nos meios de comunicação de massas, globalização, era da informação, sociedade da informação, do conhecimento e/ou do aprendizado" (Freitas, 2001, p. 89).

Isso representa um afastamento das temáticas voltadas para a informação científica e tecnológica e o redirecionamento para novas áreas de estudo.

As novas abordagens direcionam-se para o empreendedorismo privado, empresas, negócios, organizações, bem como para estudos com forte vinculação a razões econômicogerênciais, inteligência competitiva, gestão do conhecimento, gestão da qualidade, informação de valor agregado, o que "mostra a forte vinculação da CI às atividades de gestão controle, agora com justificativas de cunho histórico-econômico" (Freitas, 2001, p. 90). Essas tendências refletem as políticas do governo brasileiro. Os textos utilizados, produzidos por autores comprometidos com os interesse e políticas dos países hegemônicos, tais como os textos de assessores da presidência norte-americana e seminários da Organização para a Cooperação e Desenvolvimento Econômico (OCDE), confirmam o alinhamento com as políticas ditadas pelos Estados Unidos (EUA) para o novo mundo globalizado (Freitas, 2001).

A visão do governo brasileiro sobre os espaços que a informação ocupa e virá a ocupar no novo milênio pode ser sintetizada nas palavras do então presidente Fernando Henrique Cardoso (FHC), no prefácio do livro Sociedade em Rede, de Manuel Castells (1999):

"[...] uma sociedade globalizada e centrada no uso e aplicação da informação e na qual a divisão do trabalho se efetua, não tanto segundo jurisdições territoriais (embora isso também continue a ocorrer), mas sobretudo segundo um padrão complexo de redes interligadas. É nessa sociedade que vivemos e ela é a que devemos conhecer se quisermos que nossa ação seja ao mesmo tempo relevante e responsável" (Castells, 1999, p.III).

Esse discurso contém os elementos que balizaram o governo de FHC, quais sejam, uma crença na irreversibilidade do modelo da globalização e a necessidade inexorável do alinhamento do Brasil a esse modelo. As afirmações usadas por FHC para prefaciar o livro de Castells não seriam tão contundentes, após a instalação da crise econômica, em fins de 1999, e nos anos seguintes.
Esse discurso de alguma forma influencia os estudos da $\mathrm{CI}$, uma vez que os recortes discursivos predominantes tanto no periódico Ciência da Informação, quanto na produção discente dos alunos foram economia gerencial, política cultura e ciência. Essa predominância dos temas economia gerencial e política que assumem a liderança dos discursos em ambos os campos analisados e a conseqüente diminuição da preocupação com a ciência são, acreditamos, conseqüência do discurso da globalização e da informação enquanto instrumento que possibilita a viabilidade desse modelo.

\section{O NOVO MILENNIO - A CRISE DO MODELO NEOLIBERAL - A BUSCA DE UM CAMINHO}

O modelo neoliberal mostra-se frágil ao final de 1999 e nos anos seguintes, o que é reforçado pela eclosão do terrorismo internacional em 11 de setembro de 2001. A economia globalizada mostra sua fragilidade diante de fatos tais como uma crise no mercado imobiliário da Malásia, a crise no balanço de pagamentos do México ou da dívida externa da Argentina, que afetaram a economia de todos os países em desenvolvimento.

A globalização mostrou sua face perversa, na qual só os pobres perdem e os ricos ficam cada vez mais ricos. A dependência já não é mais de países ou de bancos, mas de investidores que pautam seu comportamento pela especulação financeira baseada muitas vezes no "palpite" de um determinado analista de empresas de consultoria que pode arruinar países "num piscar de olhos". Iniciase um movimento pela recuperação da autonomia dos Estados* nacionais, que considera fundamentais a independência econômica, para que não fiquem sujeitos aos humores do capital volátil internacional, a valorização das culturas nacionais e a valorização da produção e dos mercados internos dos países.

O governo brasileiro ignora esse movimento de questionamento da globalização, e as políticas governamentais, coerentes com a fala do presidente anteriormente citada, contemplam a informação com um ambicioso programa governamental que tem a Internet como ponto central.

No decorrer do ano 2000, é lançado pelo presidente Fernando Henrique o "Programa Sociedade da Informação (Socinfo), concebido pelo Ministério da Ciência e Tecnologia (MCT) para preparar a nova geração de redes, viabilizando um novo estágio na evolução da Internet e suas aplicações no país" (MCT,

\footnotetext{
* O Fórum Global de Porto Alegre, antítese do Fórum Global de Davos, é o mais significativo.
} 
2001), pois “[...] todos os países caminham voluntária ou involuntariamente rumo à sociedade da informação" (MCT, 2000, p.6). Esse discurso oficial apresenta o conceito acabado de uma irreversibilidade do modelo globalizante, único caminho possível para atingirmos o desenvolvimento almejado, sem o qual sucumbiremos. Aderir ao modelo, em que o mercado é o senhor da sociedade, significa, de acordo com esse discurso, a promessa de redenção e desenvolvimento do país.

O Plano Plurianual 2000-2004, coerente com esse discurso, apresenta como meta:

“[...] aumentar substancialmente a participação da economia da informação no Produto Interno Bruto (PIB) - hoje estimada em 10\%. A indústria e as empresas brasileiras deverão ser os setores mais beneficiados, tornando-se mais competitivas no mercado internacional [e como um de seus objetivos] contribuir para reduzir as desigualdades sociais e regionais" [o que deverá ser atingido através da] disseminação do uso do computador em todo território nacional e [pela criação de] condições para que o maior número de brasileiros possa acessar a Internet" (MCT, 2001).

Em síntese, o Programa Sociedade da Informação possibilitará, por meio da ampliação da Internet no país, de acordo com seu discurso:

- melhorar a competitividade da indústria brasileira;

- diminuir as desigualdades sociais e regionais;

- propiciar a colaboração e condução de experimentos cooperativos e disseminação de informação científica e tecnológica;

- realizar educação a distância de qualidade;

- criar bibliotecas temáticas digitais;

- aumentar a criação e difusão cultural;

- criar serviços de referência em atendimento e informação em saúde;

- ser instrumento habilitador de competências e de participação social;

- criar ambientes de comércio eletrônico e transações seguras;

- integrar e maximizar as ações públicas para a cidadania, transparência das ações e melhoria da qualidade dos serviços;

- realizar treinamento e formação tecnológica para popularizar a cultura digital.

Ci. Inf., Brasília, v. 33, n. 1, p. 91-100, jan./abril 2004
Pelo discurso colocado na Socinfo, a Internet pode significar a "redenção" do país. Entretanto, em nosso entender, a disseminação da Internet em si não resolve qualquer problema, pois alguns pressupostos, além da melhoria do sistema de telecomunicações, que é relativamente simples e rápida, têm de haver com o aumento do nível de escolaridade da população brasileira, na qual o índice de analfabetismo funcional* beira os 70\% (Sader, 2000, p. 12). Essa população não apenas deve formar-se e informar-se via rede, mas também deve utilizá-la de forma efetiva e eficiente para que a maioria dos objetivos propostos seja atingida.

Diante dessa nova proposta governamental, o Ibict assume função apenas de administrador de bancos de dados, e seu Departamento de Ensino e Pesquisa (DEP), que foi por 45 anos formador de recursos humanos e esteve na vanguarda da CI no país, está em processo de extinção, e seus cursos de pós-graduação, de acordo com orientação do MCT, devem ser transferidos para a universidade.

\section{CONCLUSÕES}

A ciência da informação no Brasil, em seus quase 50 anos de existência, conviveu com propostas e modelos políticos diversos e antagônicos, democráticos ou autoritários, nacionalistas ou internacionalistas. A influência desses modelos foi marcante nos caminhos trilhados. A influência norte-americana sobre o país, seja na área econômica, industrial, científica ou cultural, é sentida quando, ao final da década de 60, a CI abandona a lógica que a orientava e assume o programa preconizado pelo seminário $\mathrm{CNPq/Usaid,} \mathrm{ou} \mathrm{seja,} \mathrm{a} \mathrm{informação} \mathrm{a}$ serviço do desenvolvimento econômico do país.

As políticas colocadas pelo governo para "a Sociedade da Informação do novo milênio" constituem um equívoco sobre o que seja, realmente, a informação e sua função na sociedade. Entretanto, no presente momento, os profissionais da CI parecem não ter fôlego para interferir na formulação dessas políticas de informação que se restringem a uma "vulgarização da Internet".

Entretanto, acreditamos que, quando a indignação com as irresponsabilidades dos governantes de plantão atingirem parcela mais ampla da sociedade e houver uma organização mais efetiva desses segmentos, a reação virá para, mesmo à custa de algum retrocesso, como sempre acontece na história, colocar a CI no lugar que deve ocupar na ciência e na sociedade brasileiras.

Artigo recebido em 28-10-2003 e aceito para publicação em 24-04-2004.

* "Analfabeto funcional" é o indivíduo incapaz de, ao ler uma carta, entender seu conteúdo e respondê-la (Sader, 2000, p. 12). 


\section{Eduardo Vieira Martins}

\section{REFERÊNCIAS}

ARAÚJO, V. M. R. H., Sistemas de recuperação de informação: uma nova abordagem teórico-conceitual. 1994. 1 v. Tese (Doutorado em Comunicação e Cultura) - Escola de Comunicação, Universidade Federal do Rio de Janeiro, Rio de Janeiro, 1994.

AZEVEDO, F. (Org.). As ciências no Brasil. Rio de Janeiro : EDUFRJ, 1994.

BELKIN, N. J.;ROBERTSON, S. E. Information science and the phenomenon of information. Journal of the American Society for Information Science, Washington, v. 27, n. 4, p. 197-204, July/Aug. 1976.

BRASIL. Ministério da Ciência e Tecnologia. Programa Sociedade da Informação. Disponível em: <www.mct.gov.br/Temas/Socinfo>. Acesso em: 27 nov. 2001.

Sociedade da Informação no Brasil: livro verde. Brasília, 2000.

CASTEllS, M. A sociedade em rede. São Paulo : Paz e Terra, 1999.

CARDOSO, F. H. Empresário industrial e desenvolvimento econômico do Brasil. São Paulo : DIFEL, 1964.

Prefácio. In: CASTELLS, M. A sociedade em rede. São Paulo : Paz e Terra, 1999.

CHRISTOVÃO, H. T. A ciência da Informação no contexto da pósgraduação do Ibict. Ciência da Informação, Brasília, v. 24, n. 1, p. 31 35, jan./abr. 1995.

CONSELHO NACIONAL DE DESENVOLVIMENTO CIENTÍFICO E TECNOLÓGICO. História. Disponível em: <http://www.cnpq.br/ sobrecnpq/historia/index.htm>. Acesso em: 06 maio 2001.

DANTAS, M. Trabalho com informação: investigação inicial para um estudo na teoria do valor. 1994. 1 v. Dissertação (Mestrado em Ciência da Informação) - Escola de Comunicação, Universidade Federal do Rio de Janeiro, Rio de Janeiro, 1994.
FREITAS, L. S. Na teia dos sentidos: análise do discurso da ciência da informação sobre a atual condição da informação. 2001. 1 v. Tese (Doutorado em Ciências) - Escola de Comunicação e Artes, Universidade de São Paulo, São Paulo, 2001.

MIKHAILOV, A. I., Information science and an informed society. ASIS Bulletin, v. 10, n. 1, p. 14-17, Oct. 1983.

MOREL, R. L. M. Ciência e Estado: a política científica no Brasil. São Paulo: T. A. Queiroz, 1979.

MORIN, E. Ciência com consciência. Rio de Janeiro : Bertrand do Brasil, 1999.

MOTOYAMA, S.; MARQUES, P. Q. A história da tecnologia nuclear brasileira: um festival de equívocos. In: VARGAS, M. (Org.). História da técnica e da tecnologia no Brasil. São Paulo : UNESP, 1994. p. 399. 412 .

PINHEIRO, L. V. R. A Ciência da Informação entre sombra e luz: domínio epistemológico e campo interdisciplinar. 1997. 1 v. Tese (Doutorado em Comunicação e Cultura) - Escola de Comunicação, Universidade Federal do Rio de Janeiro, Rio de Janeiro, 1997.

RIBEIRO, J. C. A física no Brasil. In: AZEVEDO, F. (Org.). As ciências no Brasil. Rio de Janeiro : EDUFRJ, 1994.

SADER, E. Século XX: uma biografia não autorizada - o século do imperialismo. São Paulo : Fundação Perseu Abramo, 2000.

SANTOS, S. G. M. Estado, ciência e autonomia: da institucionalização à recuperação de Manguinhos. 1999. 1 v. Dissertação (Mestrado em História Social) - Instituto de Filosofia e Ciências Sociais, Universidade Federal do Rio de Janeiro, Rio de Janeiro, 1999.

SOUZA, F. C. O ensino da biblioteconomia no contexto brasileiro. Florianópolis: EDUFSC, 1990.

VARGAS, M. (Org.). História da técnica e da tecnologia no Brasil. São Paulo: UNESP, 1994. p. 399-412.

ZAHER, C. R. Entrevista. Ciência da Informação, Brasília, v. 24, n. 1, p. 13-20, jan./abr. 1995. 